\title{
Research on cutting characteristics of fiber bundle with high-speed photography
}

\author{
Zhitao $\mathrm{He}^{1,2}$, Huiling Ding ${ }^{2}$, Sanming $\mathrm{Du}^{3}$, Zhen $\mathrm{Li}^{3}$, Jiangtao $\mathrm{Ji}^{2}$, Jian $\mathrm{Li}^{1}$, Yongzhen Zhang ${ }^{3 *}$ \\ (1. Wuhan Research Institute of Materials Protection, China Academy of Machinery Science and Technology, Wuhan 430030, China; \\ 2. College of Agricultural Equipment Engineering, Henan University of Science and Technology, Luoyang 471023, China; \\ 3. National United Engineering Laboratory for Advanced Bearing Tribology, Henan University of Science and Technology, \\ Luoyang 471023, China)
}

\begin{abstract}
Cutting is an essential and complicated process in many fields. Efficient and low-consumption cutting operations are of great significance for environmental protection and energy conservation. The development of high performance cutting parts relies on a deep understanding of the cutting process and cutting mechanism. In this research, a new type of cutting test bench with high-speed photography was developed, and the cutting tests were conducted on the jute fiber bundle from quasi-static cutting at $10 \mathrm{~mm} / \mathrm{s}$ to dynamic cutting in the speed range of $0.6-2.4 \mathrm{~m} / \mathrm{s}$. The cutting process was captured by a high-speed camera. Analysis shows that compression exists before quasi-static cutting, and the compression force curve with respect to the compression ratio follows an exponential function. The cutting speed has a significant effect on cutting energy. The cutting energy consumption is not a monotonous function of cutting speed owing to the combined effect of elastic deformation and friction of fibers. The cutting energy increases with increasing cutting speed in the range of 0.6-1.2 m/s due to the increase of the friction within fibers and the friction between the blade and fibers. The cutting energy decreases with increasing cutting speed in the range of 1.2-1.8 m/s, and tends to be a fixed value when the cutting speed exceeds $1.8 \mathrm{~m} / \mathrm{s}$ due to the stabilized elastic deformation and friction coefficient. From the perspective of energy saving, it is meaningless to increase the blade speed excessively when cutting fiber bundles.
\end{abstract}

Keywords: jute fiber, cutting, high-speed photography, energy consumption, friction

DOI: $10.25165 /$ j.ijabe.20201303.5677

Citation: He Z T, Ding H L, Du S M, Li Z, Ji J T, Li J, et al. Research on cutting characteristics of fiber bundle with high-speed photography. Int J Agric \& Biol Eng, 2020; 13(3): 94-99.

\section{Introduction}

Agriculture produces a vast amount of stalks every year, and in maximum reports, it disposed of either by burning, dumping or unplanned landfilling ${ }^{[1]}$. Considering the rapid rising of the share of renewable energy in total primary energy supply, agricultural by-products are the most important renewable raw material. However, they have to go through a pretreatment stage of cutting before any subsequent procedure ${ }^{[2]}$.

Therefore, cutting is an inevitable procedure in agriculture, e.g. ploughing, burrowing, sheep shearing and harvesting of crops. However, cutting is one of the most energy-intensive or energy-inefficient operations. Given the expected scale of future biomass energy utilization, any improvement in efficiency or energy reduction in the cutting process means substantial energy saving $^{[2]}$.

Received date: $2020-01-14 \quad$ Accepted date: $2020-03-30$

Biographies: Zhitao He, $\mathrm{PhD}$ candidate, research interests: performance improvement of farm machinery and its key components, Email: hzt@haust.edu.cn; Huiling Ding, PhD, Associate Professor, research interests: farm machine and mechanical reliability, Email: ding-huiling@163.com; Sanming Du, PhD, Professor, research interests: friction and surface engineering, Email: dsming@ @aust.edu.cn; Zhen Li, PhD, Associate Professor, research interests: surface engineering, Email: lizhen@ haust.edu.cn; Jiangtao Ji, $\mathrm{PhD}$, Professor, research interests: farm machine and mechanical reliability, Email: jjt0907@163.com; Jian Li, PhD, Professor, research interests: friction and surface engineering, Email: lijianwuhan@tom.com.

*Corresponding author: Yongzhen Zhang, $\mathrm{PhD}$, Professor, research interests: friction and wear. Henan University of Science and Technology, Luoyang 471003, China. Tel: +86-379-64231003, Email: yzzhang@ haust.edu.cn.
Unfortunately, the interaction of rigid blades and flexible nonmetal biomass is not as well understood as that of industrial cutting such as machine tool cutting. Even with a use of an elementary edge, the cut of plant material is a very complicated process due to its structural heterogeneity and biological diversity ${ }^{[3]}$.

Different kinds of stalks demonstrate different mechanical properties in cutting processes, even for the same kind of stalks, the mechanical properties are different due to different crop maturity, moisture content and planting location, etc. Most of the previous studies ${ }^{[2-10]}$ on plant stem cutting use a specific type of stem as the sample, despite the fact that many valuable conclusions were revealed, nevertheless, it's still difficult to explain or predict the cutting characteristics of other plant materials.

Structurally, the stalks can be viewed as materials with fibers of high tensile strength oriented in a common direction and bound together by the material of much lower strength ${ }^{[11-13]}$. Studies also evidenced that the mechanical properties of plant stalks accord with characteristics of composite material ${ }^{[12,14-16]}$. As a result, taking stalks as plant fiber reinforced composites, and conducting researches on the reinforcement phase firstly would be a valuable way to discover the cutting characteristics of plant stalks. Unfortunately, a review of the literature revealed little information from this perspective.

This contribution aims to take jute fiber bundle as the specimen and conduct tests on the cutting process from quasi-static to dynamic cutting using an elementary straight edge. This work was expected to contribute to an understanding of the cutting process of pure plant fiber bundle, and to provide valuable aid for 
designing biomass or fiber bundle cutting equipment.

\section{Design of test bench}

\subsection{Mechanical structure and sensor system}

Figure 1 presents the main structure of the test bench, which consists of blade assembly, guide rails, lifting assembly and high-speed camera. The cutting blade assembly was able to slide along the guide rails. The frictional was reduced significantly by installing linear bearings between cutting blade assembly and guide rails.

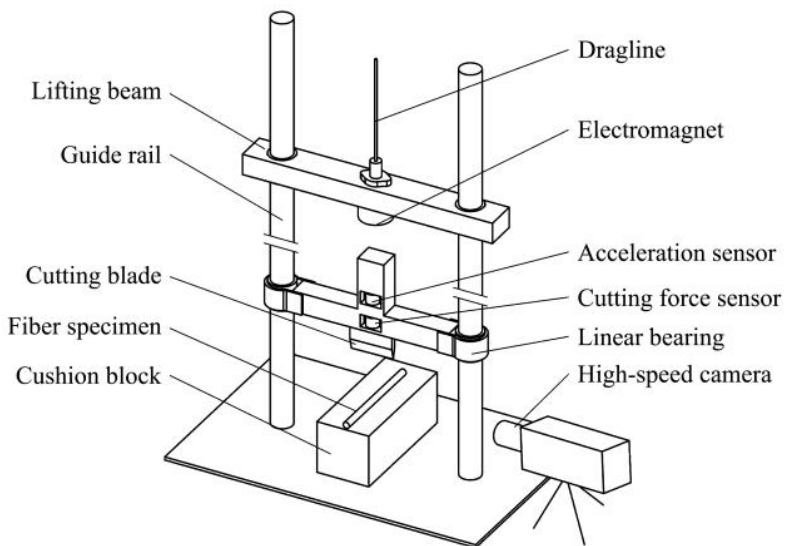

Figure 1 Schematic diagram of test bench

In order to acquire real-time cutting force and acceleration data, a piezoelectric force sensor and a piezoelectric acceleration sensor were installed at the back of the cutting blade respectively. The two sensors were placed coaxially, and the axis coincided with the cutting force direction as shown in Figure 1.

The main parameters of the force sensor and the acceleration sensor are listed in Table 1.

Table 1 Main parameters of sensors

\begin{tabular}{lcc}
\hline Characteristics & Force sensor & Acceleration sensor \\
\hline Range & $1000 \mathrm{~N}$ & $2500 \mathrm{~m} \cdot \mathrm{s}^{-2}$ \\
Sensitivity & $5 \mathrm{mv} / \mathrm{N}$ & $2 \mathrm{mv} / \mathrm{m} \cdot \mathrm{s}^{-2}$ \\
Natural frequency & $40 \mathrm{kHz}$ & $35 \mathrm{kHz}$ \\
Linear error & $<1 \% \mathrm{FS}$ & $<1 \% \mathrm{FS}$ \\
Weight & $10 \mathrm{~g}$ & $14 \mathrm{~g}$ \\
\hline
\end{tabular}

The height of the lifting beam was controlled by a servo motor, and an electromagnet was fixed under the lifting beam. When the electromagnet was activated, the tool rest was attracted to the lifting beam and slid up synchronously along the cylindrical guide rails. The tool rest plummeted and cut the specimen when the electromagnet was turned inactive.

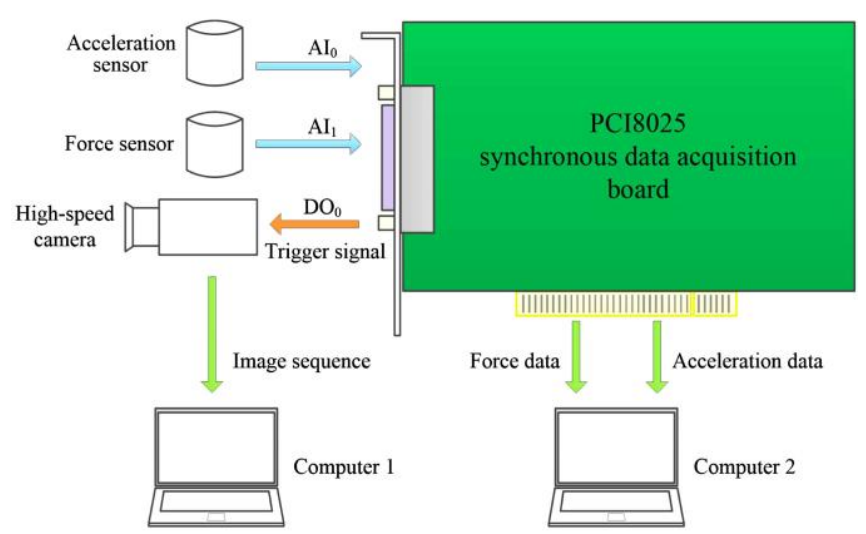

Figure 2 Schematic diagram of signal flow
A 4-channel synchronous data acquisition board (type PCI8025) was used to ensure the synchronicity of all signals in each test. The force sensor and the acceleration sensor connect with the data acquisition board through an electricity amplifier.

In order to analyze the interaction of the blade and the specimen, we use a high-speed camera type NAC MEMRECAM HX-5 to track and shoot the cutting process. The measurement software generates a trigger signal and outputs to the camera to launch tracking, as shown in Figure 2.

The electromagnet turns inactive at the beginning of each test, and the data acquisition board started to collect data from both acceleration sensor and cutting force sensor. In the meantime, the trigger signal starts the high-speed camera. Therefore, the cutting force data, the acceleration data, and the recorded images are strictly synchronized.

The camera and computer communicate using TCP/IP protocol The frame rate and image size are set to $20000 \mathrm{fps}$ and $320 \times$ 480 pixels respectively during each test. The estimated cutting process lasts for 2-3 ms; therefore, approximately 40-60 frames of image are available for analysis during the cutting process.

\subsection{Measurement software}

The measurement software for this test bench was developed using the C\# programing language. In order to achieve high-speed continuous acquisition on a multi-core CPU, a data acquisition thread (DAT) and a data processing thread (DPT) were set besides the main thread. The DAT manipulates the PCI8025 board and copies data to the pre-defined buffer. The DPT converts data to a calibrated physical quantity and then sends a message to the main thread to update the data curve. Figure 3 shows the synchronization mechanism of these three threads.

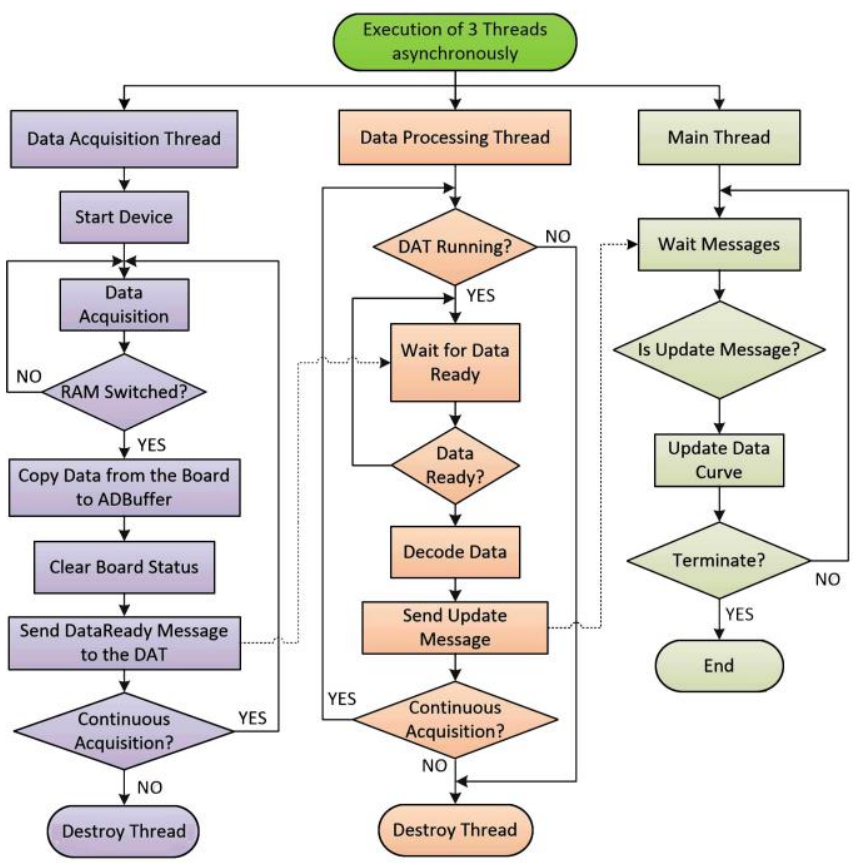

Figure 3 Execution flow chart of three threads asynchronously

\section{Cutting test using the test bench}

\subsection{Test material}

The specimens used in this experiment are three strands braided rope of jute fiber, which is made of jute (Corchorus capsularis L) through retting for bast fibers, degumming, grading, and twisting. The main compositions and characteristics of the specimen are listed in Table 2. 
Table 2 Main compositions and characteristics of the specimen

\begin{tabular}{ccccccc}
\hline $\begin{array}{c}\text { Length } \\
/ \mathrm{mm}\end{array}$ & $\begin{array}{c}\text { Diameter } \\
/ \mathrm{mm}\end{array}$ & $\begin{array}{c}\text { Cellulose Hemicellulose } \\
/ \%\end{array}$ & $\begin{array}{c}\text { Lignin } \\
/ \%\end{array}$ & $\begin{array}{c}\text { Tensile } \\
\text { Strength/MPa }\end{array}$ & $\begin{array}{c}\text { Moisture } \\
\text { Content } / \%\end{array}$ \\
\hline 100 & 6 & $59-63$ & $22-26$ & $11-17$ & $300^{1}$ & 12.7 \\
\hline
\end{tabular}

Note: The length and diameter of the specimen were $100 \mathrm{~mm}$ and $6 \mathrm{~mm}$ respectively when measuring.

The specimen is a twisted assembly of three strands of jute fibers, where single fibers are arranged in the same direction. The loose structure was observed by scanning electron microscopy, as shown in Figure 4.

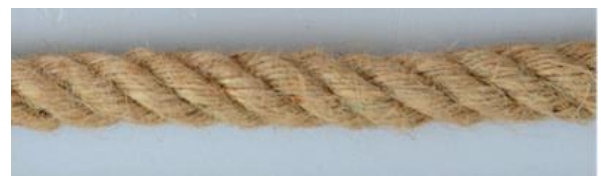

a. Appearance

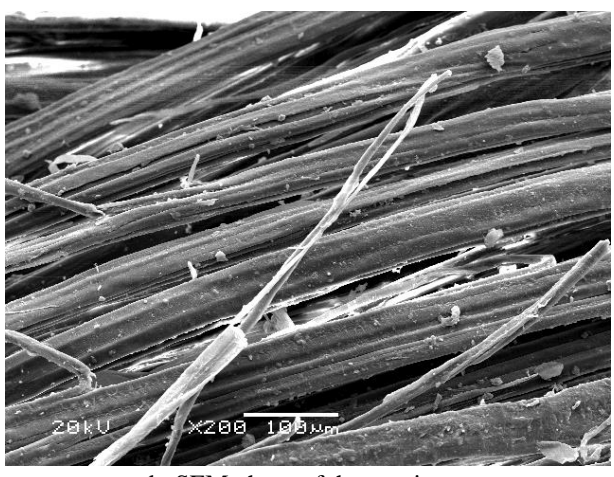

b. SEM photo of the specimen

Figure 4 Specimen used in this test

The porosity of the specimen was calculated to be 0.47 through Equation (1).

$$
p=\frac{V_{0}-V}{V_{0}}=\frac{L \pi r_{0}^{2}-L \pi r^{2}}{L \pi r_{0}^{2}}=\left(\frac{\Delta r}{r_{0}}\right)^{2}
$$

where, $r_{0}$ is the initial radius of the specimen's section, $\mathrm{mm} ; r$ is the radius of the solid part of the specimen's section, which was measured by twisting the specimen until its diameter stops decreasing before any rupture of single jute fiber, $\mathrm{mm}$.

The friction coefficient of jute fiber and blade was measured using a pin-on-disk tribometer, and the normal force was adjusted to match the force applied on the sides of the blade when cutting a jute fiber bundle. All tests were conducted at least 5 times and the average values were provided.

\subsection{Cutting blade}

All tests were conducted using a cutting blade made of high manganese steel with a blade tip angle of $30^{\circ}$. Figure 5 shows a representative optical micrograph of the blade tip. The radius of the blade tip had an average value of $(25.1 \pm 0.5) \mu \mathrm{m}$ based on measurements conducted using 3 similar images ${ }^{[17]}$. To simplify the test, the cutting edge was fixed perpendicular to the sample during all tests.

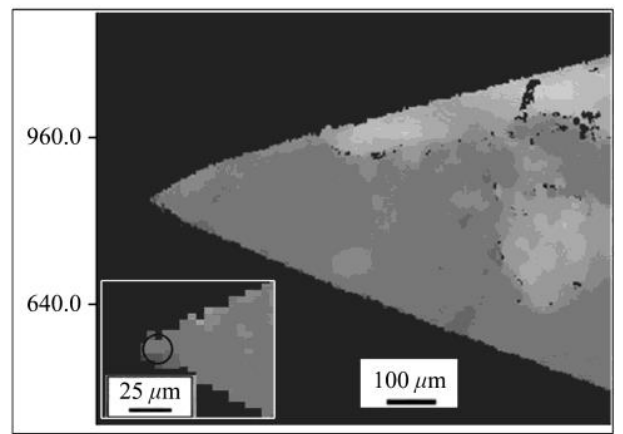

Figure 5 Representative optical micrograph of the blade tip ${ }^{[17]}$

\subsection{Test process and data analysis}

The jute fiber specimen was simply placed orthogonal to the blade edge on the aluminum cushion block. The cutting blade assembly fell vertically along the guide rails under the force of gravity from a certain height $h$ calculated using $h=v^{2} / 2 g$.

Ten speeds from the least cut off speed 0.6-2.4 m/s were set for the test. The jute fiber assemblies in this test are anisotropic, lightweight and any unexpected variations could have a relatively substantial impact on the results obtained. Therefore, all cutting tests were conducted eight times to minimize the random error. The cutting process was captured by a high-speed camera.

The cutting energy was calculated by taking the displacement of the blade edge $S(\mathrm{t})$ as an independent variable and integrating the cutting force $F(\mathrm{t})$ on $S(\mathrm{t})$. The lower limit of the integral was determined through examining the high-speed camera pictures, and the upper limit was the position that the cutting force curve drops down to minimum after cutting off.

\section{Results and discussion}

\subsection{Cutting process}

To illustrate the cutting process, we define the compression ratio $\gamma$ as the ratio of the penetration depth of the blade edge into the specimen at any stage of cutting to the diameter of the specimen, i.e.

$$
\gamma=\frac{d}{d_{0}}, \gamma \in[0,1]
$$

Due to the loose and porous structure of the specimen, a prior process of compression arises inevitably while cutting ${ }^{[16]}$. Figure 6 shows a series of pictures captured by the high-speed camera during a cutting test, which illustrate the compression process before the real cutting.

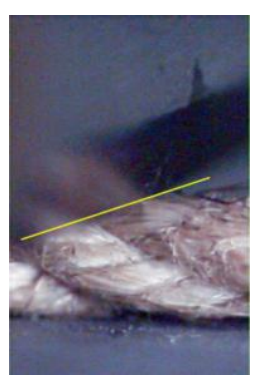

a. $\gamma=0$, the initial contact of the blade edge with the fiber, and the yellow line indicates the blade edge

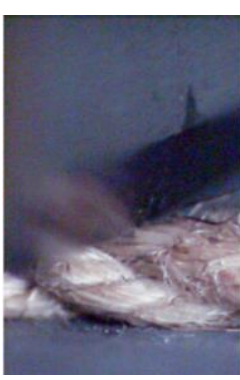

b. $\gamma=0.2$, the blade begins compressing the fiber

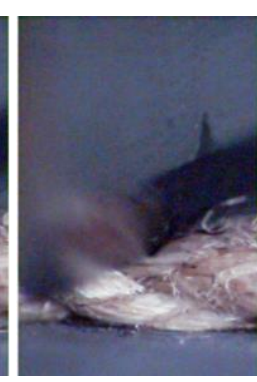

c. $\gamma=0.4$, elastic

recovery was observed before thi point

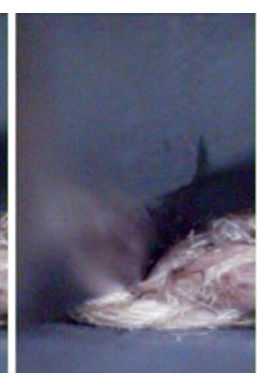

d. $\gamma=0.6$, subsequent analysis proves that the increase of the cutting force turns sharp

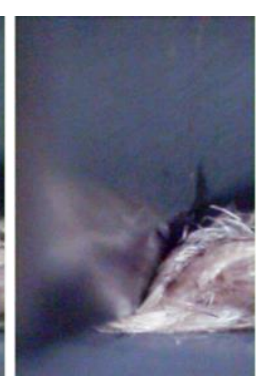

e. $\gamma=0.8$, partially rupture occurs

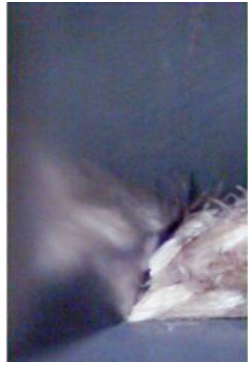

f. $\gamma=1.0$, the blade servers the fiber completely

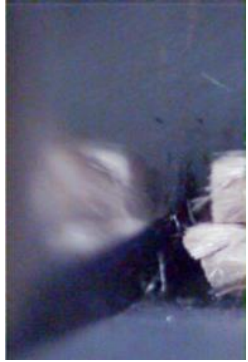

g. The fiber bounces off the blade

Figure 6 Dynamic cutting process captured by high-speed camera 
The entire fiber bundle exhibits elastic properties in the early stage of the compression process. In a quasi-static cutting test using a Universal Test Machine, the sample was unloaded and taken out when $\gamma$ reached $0.2,0.4$ and 0.6 . It was observed that few jute fibers have been severed during the compression process, and elastic recovery of compressed jute fibers has been observed.

Figure $7 \mathrm{a}$ illustrates a representative cutting process of jute fiber bundle at the speed of $10 \mathrm{~mm} / \mathrm{min}$. Curve OA can be defined as the compression period before cutting. An exponential relationship can be revealed between the cutting force $F_{\mathrm{c}}$ and the compression ratio within the compression period, i.e.

$$
F_{c}=0.638+0.078 e^{9.946 \gamma}, R^{2}=0.997
$$

The increase of the cutting force keeps unapparent until the compression rate approached the porosity value $(0.47)$ of the specimen. This phenomenon is similar to the compression characteristics of porous materials ${ }^{[18]}$. After the point $\mathrm{P}$, the loose structure of the specimen was compressed to solid-state, and the cutting force manifests a sharp increase.

Practically in each cutting force-compression ratio curve, a slight drop (point R) was observed, which can be explained by relative slip between strands or partial rupture due to uneven fiber strength $^{[19]}$.

Point A means the compressive stress exceeds the rupture strength of the fiber bundle, the specimen starts being cut ${ }^{[16]}$. Three apparent drops (after point A, B, and C) were observed in Figure $7 \mathrm{a}$, which can be interpreted as the rupture of three strands of the fiber bundle. Each drop in the curve indicates that part of the jute fibers has been ruptured and the cutting force was unloaded for a short time. The specimen was completely cut off at point $\mathrm{C}$.

Figure $7 \mathrm{~b}$ shows the process of cutting at different blade speeds. It is obvious that the maximum cutting force of dynamic cutting is much lower than that of quasi-static cutting. The jute fiber bundle behaves lower shearing strength in dynamic cutting, and this is in agreement with a number of researches on cutting plant material ${ }^{[3,20-22]}$.

In comparing Figure $7 \mathrm{~b}$ to Figure $7 \mathrm{a}$, more peaks were observed on dynamic cutting curves. The rising stage of each peak means the compression process and the falling stage means severing part of the fibers. The entire fiber bundle was thoroughly compressed into solid state before severing due to extremely low blade speed in the quasi-static cutting tests, but in the dynamic cutting tests, fibers at upper layer were compressed immediately and then severed almost simultaneously with very little compression.

The initial kinetic energy of the blade is a fixed value at the contact of the blade edge with the fiber. The compression process consumes a part of the energy, reduces the blade speed, and the remaining energy is just enough to sever a small number of jute fibers. Then the cutting resistance decreases rapidly, and the cutting continues with the next compression-cutting process until the complete fracture of the fiber bundle.

The number of fibers being severed in a single compression-cutting process increase with increasing initial kinetic energy of the blade, as a result, the number of compression-cutting peaks decreases with increasing cutting speed from 0.6 to $2.4 \mathrm{~m} / \mathrm{s}$. We noted that three of the eight replications showed a pulse-like cutting force curve with one single peak when the cutting speed was increased to $2.4 \mathrm{~m} / \mathrm{s}$, as shown in Figure $7 \mathrm{~b}$. Therefore, it can be inferred that the cutting force might be an impact as the cutting speed exceed a certain value. Ige and Finner ${ }^{[23]}$ also suggested the nature of the cutting force at impact condition was essentially an impulse.

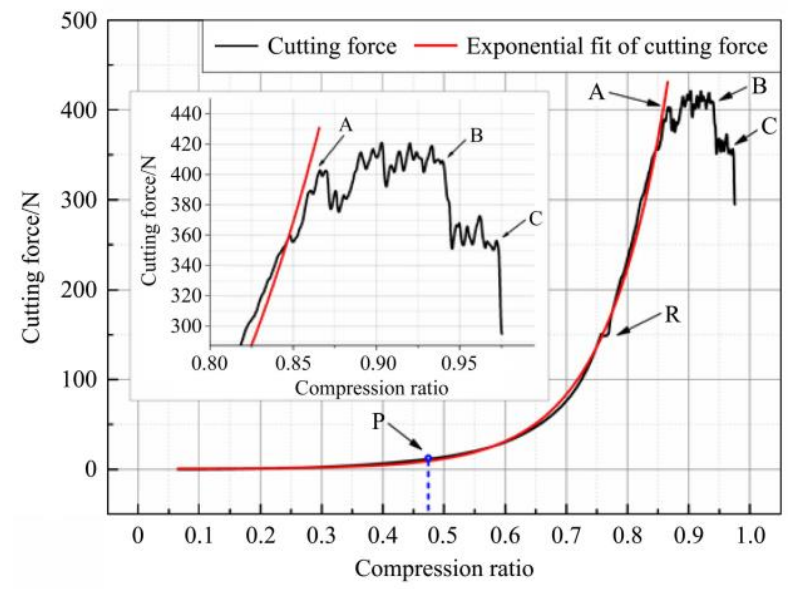

a. Quasi-static cutting, $v=10 \mathrm{~mm} / \mathrm{min}$

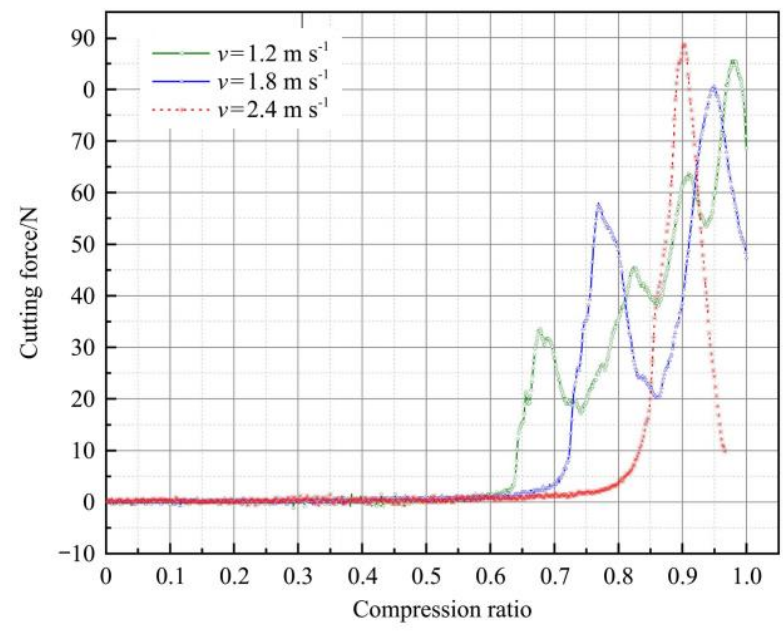

b. Dynamic cutting process

Figure 7 Cutting processes at different speeds

\subsection{Effect of cutting speed on cutting energy}

The energy consumed in a cutting with a counter shear can be given as

$$
E_{\mathrm{C}}=E_{\mathrm{n}}+E_{\mathrm{e}}+E_{\mathrm{p}}+E_{\mathrm{f}}
$$

where, $E_{\mathrm{C}}$ is the total cutting energy; $E_{\mathrm{N}}$ is the surface energy to form new surfaces; $E_{\mathrm{e}}$ and $E_{\mathrm{p}}$ are the elastic and plastic deformation energy consumption of the fibers before severing. Single jute fiber is elastic, while the fiber bundle showed a degree of plasticity during cutting due to the internal friction within single fibers. $E_{\mathrm{e}}$ is affected by the degree of elastic deformation. Higher cutting speeds of the blade result in greater inertial forces on the fiber, and the elastic deformation of the fiber decreases as the cutting speed increases before severed; $E_{\mathrm{f}}$ - the energy consumption by friction.

In Equation (4), $E_{\mathrm{e}}, E_{\mathrm{p}}$ and $E_{\mathrm{f}}$ are all closely related to speed. Therefore, it can be deduced that cutting speed has a significant influence on cutting energy. The most interesting finding in this work was that the cutting energy consumption is not a monotonous function of cutting speed.

Figure 8 presents the relationship between blade velocity and cutting energy requirement for jute fiber bundle. It shows that the cutting energy consumption increased with increasing blade velocity in the speed range of $0.6-1.2 \mathrm{~m} / \mathrm{s}$, and the maximum value reaches $75.0 \mathrm{MJ}$ corresponding to the blade velocities of $1.2 \mathrm{~m} / \mathrm{s}$.

The increasing trend was similar as compared to those reported by Mathanker et al. ${ }^{[9]}$ on energy cane stems, Prasad and Gupta ${ }^{[21]}$ on maize stalk, Yiljep and Mohammed ${ }^{[10]}$ on sorghum stalks and Alireza $^{[24]}$ on rice stems, but with a different origin. These 
researches indicated that more energy imparted by the knife at high knife speed wasted since more energy was transmitted in accelerating the separated parts of the stalk after cutting. Johnson et al. ${ }^{[25]}$ supposed that more energy was transferred to the stem at higher speed which might be absorbed in impact, vibration and deflection. Elastic deformation of the fibers consumes too much energy in this test due to the existence of the cushion block as a counter edge.

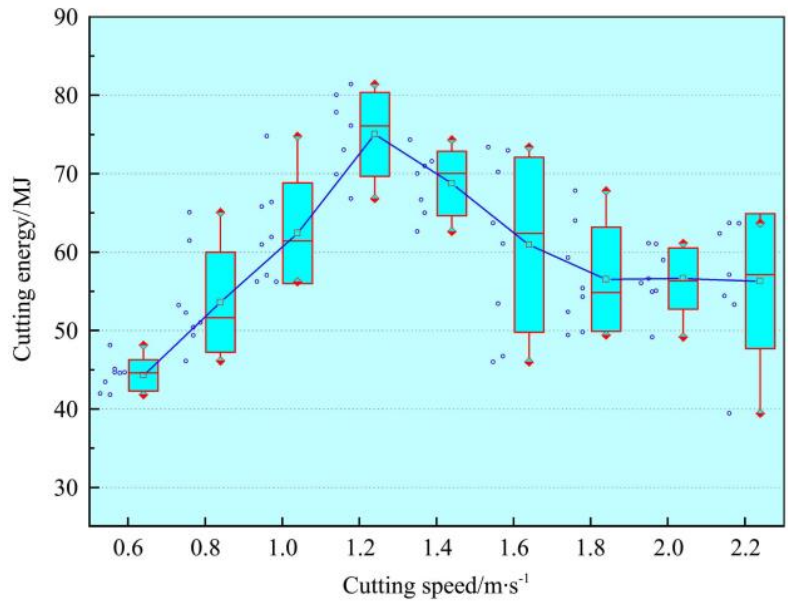

Figure 8 Effect of cutting speed on cutting energy

It was clearly observed through high-speed photography that fibers have been bent, displaced and misaligned relatively during the compression and cutting process. Therefore, energy consumed by deformation, the friction within single jute fibers, and the friction between fibers and blade should not be ignored. To verify the effect of friction on cutting, a comparative test was conducted. The low-viscosity silicone oil was used to minimize the friction within fiber bundles as well as the friction between the blade and the specimen.

The friction coefficient of the blade and the fiber as a function of speed is consistent with that of the cutting energy in the speed range of $0.6-1.2 \mathrm{~m} / \mathrm{s}$. The maximum cutting force reduced by $2.34 \%-11.84 \%$ in the speed range of $0.6-1.4 \mathrm{~m} / \mathrm{s}$, with an average reduction of $5.93 \%$ when using silicone oil for lubrication, as shown in Figure 9. As a result, the increase in cutting energy consumption in the speed range of $0.6-1.2 \mathrm{~m} / \mathrm{s}$ can be explained by the increase of the friction between the blade and the jute fiber, and the relatively slow decrease of the elastic deformation. In the speed range of 2.0-2.4 m/s, the effect of friction on cutting force is not significant.

The cutting energy decreases with increasing cutting speed over $1.2 \mathrm{~m} / \mathrm{s}$ and tends to a stable value of $(56.5 \pm 0.2) \mathrm{MJ}$ after $1.8 \mathrm{~m} / \mathrm{s}$. This trend is in agreement with the research of Kakitis et al. ${ }^{[26]}$ on cutting hemp fibers, Neugebauer et al. ${ }^{[27]}$ on cutting metals, and McRandal and McNulty ${ }^{[28]}$ on cutting forage crops.

In the speed range of $1.2-1.8 \mathrm{~m} / \mathrm{s}$, the increasing trend of the friction coefficient gradually slows down, and the elastic deformation of the fiber before severing decreases at a faster rate. As a result, at higher cutting speeds, the fibers closest to the blade edge are severed first with relatively smaller deformation, while the other fibers are not compacted in the meantime. Therefore, the overall energy consumption for cutting decreases.

Cutting energy is the result of the combined action of $E_{\mathrm{e}}, E_{\mathrm{p}}$ and $E_{\mathrm{f}}$. The friction coefficient tends to be stable, and the effect of friction weakened when the cutting speed exceeds $1.8 \mathrm{~m} / \mathrm{s}$. The elastic deformation of the fiber also tends to be stable; consequently, the cutting energy consumption appears stable.
Therefore, from the perspective of saving energy, it is meaningless to increase the cutting speed excessively.

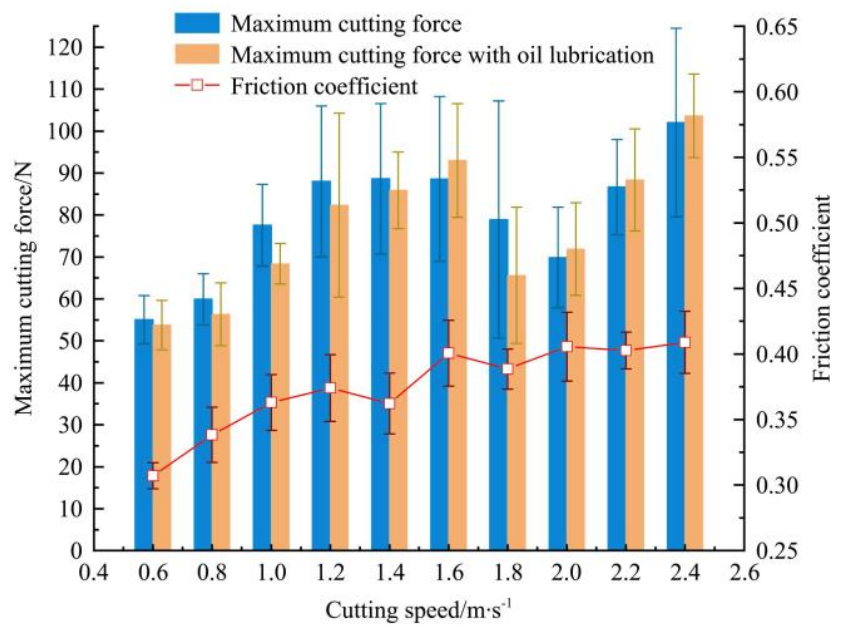

Figure 9 Effect of cutting speed on the friction coefficient and cutting force

\section{Conclusions}

A new type of cutting test bench was designed, in which high-speed cameras and high natural frequency sensors were used to acquire detailed information during the cutting process. The measurement software for this test bench was programmed using multi-threaded technology.

Jute fiber bundle shows different characteristics in quasi-static cutting and dynamic cutting. There exists an obvious compression process before rupture in a quasi-static cutting, and the compression force follows an exponential function curve. Quasi-static cutting consumes much more energy than dynamic cutting due to thoroughly compression before severing. The compressing-cutting process repeats in the dynamic cutting test until complete rupture of the fiber bundle. The cutting force has a tendency to turn into an impact when the blade speed exceeds $2.4 \mathrm{~m} / \mathrm{s}$.

The cutting speed has a significant effect on energy consumption. However, the cutting energy consumption is not a monotonous function of cutting speed. The cutting energy increases with increasing cutting speed in the range of $0.6-1.2 \mathrm{~m} / \mathrm{s}$ due to the effect of friction. The cutting energy decreases with increasing cutting speed in the range of 1.2-1.8 m/s, and tends to be a fixed value when the cutting speed exceeds $1.8 \mathrm{~m} / \mathrm{s}$.

\section{Acknowledgements}

This work was financially supported by the National Key Research and Development Program of China (Grant No. 2017YFD0700502) and the National Natural Science Foundation of China (Grant No. 51705136 and 51375146).

\section{[References]}

[1] Sadh P K, Duhan S, Duhan J S. Agro-industrial wastes and their utilization using solid state fermentation: a review. Bioresour Bioprocess 2018; 5: 1. Doi: 10.1186/s40643-017-0187-z.

[2] Igathinathane C, Womac A R, Sokhansanj S. Corn stalk orientation effect on mechanical cutting. Biosyst Eng, 2010; 107: 97-106.

[3] Szymanek M. Analysis of cutting process of plant material. Teka Comm Mot Power Ind Agric, 2007; 07A: 107-113.

[4] Shahbazi F, Nazari Galedar M. Bending and shearing properties of safflower stalk. J Agric Sci Technol, 2012; 14: 743-754.

[5] İnce A, Uğurluay S, Güzel E, Özcan M T. Bending and shearing 
characteristics of sunflower stalk residue. Biosyst Eng, 2005; 92: 175-181

[6] Ozdemır G, Sessiz A, Esgicı R, Elicin A K. Cutting properties of wine grape cultivars. Sci Pap - Ser B Hortic 2015; lix: 151-158.

[7] Jin X, Yuan Y, Ji J, Zhao K, Li M, Chen K. Design and Implementation of Anti-Leakage Planting System for Transplanting Machine Based on Fuzzy Information. Comput. Electron. Agric., 2020; 169: 105204.

[8] Ghahraei O, Ahmad D, Khalina A, Suryanto H, Othman J. Cutting tests of kenaf stems. Trans ASABE, 2011; 54: 51

[9] Mathanker S K, Grift T E, Hansen A C. Effect of blade oblique angle and cutting speed on cutting energy for energycane stems. Biosyst Eng, 2015; 133: 64-70.

[10] Yiljep Y D, Mohammed U S. Effect of knife velocity on cutting energy and efficiency during impact cutting of sorghum stalk. Agric Eng Int CIGR EJournal, 2005; 7: 314-320.

[11] Srivastava A K, Goering C E, Rohrbach R P, Buckmaster D R. Engineering principles of agricultural machines. 2nd ed. MI, USA: ASABE, 2012.

[12] Shen C, Li X, Tian K, Zhang B, Huang J, Chen Q. Experimental analysis on mechanical model of ramie stalk. Transactions of the CSAE, 2015; 31(20): 26-33. (in Chinese)

[13] Guo W, Wang F, Huang G, Zhang F, Wei S. Experiment on mechanical properties and chemical compositions of wheat stems. Transactions of the CSAM, 2009; 40: 110-114. (in Chinese)

[14] Jin X, Li D, Ma H, Ji J, Zhao K, Pang J. Development of Single Row Automatic Transplanting Device for Potted Vegetable Seedlings. Int J Agric \& Biol Eng, 2018; 11(3): 67-75

[15] Zhou Y, Li X, Shen C, Tian K, Zhang B, Huang J. Experimental analysis on mechanical model of industrial hemp stalk. Transactions of the CSAE, 2016; 32: 22-29. (in Chinese)

[16] Liang L, Zhao X. Fiber reinforcement effect of the corn stalk skin. 2012 Int. Conf. Mater. Eng. Autom. Control ICMEAC 2012, April 27-29, 2012, Trans Tech Publications, 2012; 562-564: 1121-1125.

[17] Ding H, Zhang Y, He Z. Fracture failure mechanisms of long single PA6 fibers. Polymers, 2017; 9: 243

[18] Berzins R, Kakitis A, Berzins U, Cukurs J. Hemp fiber and shive coefficient of friction. Eng. Rural Dev., Latvia University of Agriculture, Faculty of Engineering Jelgava, LUA, 2013; pp.526-530.

[19] Huang F, Yang T W, Li Z J, Li Z H, Jin Q L, Zhou R. Anisotropic compressive properties of ordered porous copper. Chin J Nonferrous Met 2011; 21: 604-610.

[20] Berzins R, Kakitis A, Berzins U, Cukurs J. Evaluation of hemp straw and fibre strength. Eng. RURAL Dev., vol. 13, Jelgava, Latvia: 2014; pp.198-203

[21] Dowgiallo A. Cutting force of fibrous materials. J Food Eng, 2005; 66: 57-61.

[22] Prasad J, Gupta CP. Mechanical properties of maize stalk as related to harvesting. J Agric Eng Res, 1975; 20: 79-87.

[23] Zhang L, Li M, Pei Y, Liu Z. Cutting weed with an improved test bench and measurement of cutting resistance. J Hunan Agric Univ, 2014; 39: 99-102. (in Chinese)

[24] Ige M T, Finner M F. Forage harvester knife response to cutting force Transactions of the ASAE, 1976; 19: 0451-0454.

[25] Allameh A, Reza Alizadeh M. Specific cutting energy variations under different rice stem cultivars and blade parameters. Idesia Arica, 2016; 34 : 11-17.

[26] Johnson P C, Clementson C L, Mathanker S K, Grift T E, Hansen A C. Cutting energy characteristics of Miscanthus $\mathrm{x}$ giganteus stems with varying oblique angle and cutting speed. Biosyst Eng, 2012; 112: 42-48.

[27] Kakitis A, Berzins R, Berzins U. Cutting energy assessment of hemp fibres. Eng. Rural Dev., Latvia University of Agriculture, Faculty of Engineering Jelgava, LUA, 2015; pp.140-145.

[28] Neugebauer R, Bouzakis K-D, Denkena B, Klocke F, Sterzing A, Tekkaya A E, et al. Velocity effects in metal forming and machining processes. CIRP Ann - Manuf Technol, 2011; 60: 627-650.

[29] McRandal D M, McNulty P B. Impact cutting behaviour of forage crops I. Mathematical models and laboratory tests. J Agric Eng Res, 1978; 23: 313-328. 